\title{
A "mãe-toda" e a alienação parental: uma abordagem Freudo-Lacaniana
}

\section{The "all-mother" and Parental Alienation: a Freudian- Lacanian approach}

\author{
Marcele teixeira Homrich ravasio* \\ Márcia Aparecida Vitorello*
}

\section{Resumo}

O presente texto tem como objetivo articular a compreensão psicanalítica sobre a função materna e a alienação parental. Inicialmente, busca-se desconstruir a maternidade como concepção natural e instintiva, sendo compreendida na relação com o grande Outro, o seu saber inconsciente sobre a maternidade e a filiação. Para tanto, utiliza-se a abordagem freudo-lacaniana para desdobrar o conceito de mãe-toda - aquela que detém o filho como objeto de seu gozo, produzindo a alienação parental. Para finalizar, conclui-se que a lei promulgada por uma autoridade legal, além de produzir um corte na convivência parental, pode incidir como um corte simbólico na relação da mãe-filho.

Palavras-chave: Alienação parental. Psicanálise. Função materna.

\section{Abstract}

the objective of the present text is to articulate the psychoanalytic comprehension about maternal function and parental alienation. Initially it attempted to deconstruct maternity as a natural and instinctual concept, being unconscious about motherhood and childhood. In doing so, it utilizes a Freudian-Lacanian approach to unfold the concept of an all-mother, as one who detains their child as an object for their own enjoyment producing parental alienation. In conclusion

Doutora em Educação pela UFRGS na linha de pesquisa Educação e Psicanálise, e professora titular do Instituto Cenecista de Ensino Superior de Santo Ângelo - IESA. Santo Ângelo - RS Brasil. Email: celehomrich@ibest.com.br

* Psicóloga (PUC/RS), Mestre em Psicologia Social e da Personalidade (PUC/RS). Doutora em Educação pela UFRGS no eixo de pesquisa educação e psicanálise. Navegantes - RS - Brasil. 
the law promoted by legal authority, beyond producing a rift in the parental relationship, one can infer it as a symbolic rift in the relationship between mother and child.

Key Words: Parental Alienation. Psychoanalysis. Maternal Function.

\section{Introdução}

Na cultura ocidental, a mãe é uma figura mítica. Espera-se dela uma atitude amorosa, acolhedora e devotada em relação ao filho. No imaginário social, a mãe é a encarnação do bem supremo, do amor incondicional, e a maternidade é entendida como um atributo natural feminino. Será mesmo a maternidade um dom? A maternidade e o amor estão inscritos desde sempre na mulher?

Ao recorrermos às representações construídas e veiculadas socialmente em torno da mãe, como acontece na publicidade, encontramos uma mulher com semblante feliz, brilhante, satisfeito, devido ao acordo perfeito estabelecido com a sua criança.

Por outro lado, no discurso social, também encontramos provérbios como "ser mãe é padecer no paraíso" e "os filhos devem ser criados para o mundo". Sobre isso, diz Jose Saramago (2011, p.38):

Devemos criar os filhos para o mundo. Torná-los autônomos, libertos, até de nossas ordens. A partir de certa idade, só valem conselhos. [...] Ser pai ou mãe é o maior ato de coragem que alguém pode ter, porque é se expor a todo tipo de dor, principalmente incerteza de estar agindo corretamente e do medo de perder algo tão amado. Perder? Como? Não é nosso, recordam-se? Foi apenas um empréstimo!

Ambos os provérbios trazem saberes acerca da mãe e a respeito deles gostaríamos de refletir. No primeiro, observamos haver na atividade da mãe a coexistência de um sofrimento e de um prazer naquilo que concerne aos filhos. Ora, na abordagem psicanalítica, prazer misturado 
com sofrimento na relação do sujeito com o objeto implica em gozo. O segundo provérbio traz a ideia de separação ou libertação do filho da tutela familiar. Algo como permitir ou oferecer um passaporte a um sujeito dependente para ir ao encontro do mundo e nele tornar-se um cidadão.

Sabemos que os ditados populares são formulados a partir de saberes da cultura. Desde aí, podemos interrogar o que está em jogo na maternidade, pois nela aparecem operações mentais distintas de uma mera programação instintiva, tal como ocorre no mundo dos animais. Então, a mãe não é guiada pelo instinto?

Para a antropóloga Badinter (1980), o amor não é inato ou instintual, pois a mulher é um ser de desejo, inserida num campo simbólico e cultural. A relação da mulher com a maternidade não pode ser explicada pela "voz do ventre" ou "natureza feminina", mas por fatores psíquicos, sociais e históricos. Ao analisar documentos e obras de historiadores de costumes, Badinter (1980) mostra como as mães do século XVIII eram indiferentes aos filhos. Nessa época, havia o costume de as mulheres confiarem seus filhos às amas de leite e, devido à insuficiência nos cuidados, a taxa de mortalidade infantil era elevada: "Graças a Marcel Lanchiver, os historiadores dos costumes conhecem bem o caso de Marie Bienvenue, ama negligente que deixou morrer trinta e uma crianças em cerca de catorze meses." (BADINTER, 1980, p. 12). Mesmo sabendo desses casos, as mães continuavam entregando seus filhos aos cuidados das amas. Assim, a autora mostra haver momentos históricos em que há "falhas" em relação ao exercício da maternidade, relacionando-as às aspirações e ideais vigentes naquela sociedade.

Apesar de estar fundamentada no campo da antropologia, a ideia de maternidade "desnaturada"1 converge com os pressupostos da psicanálise, que considera o sujeito como um ser de linguagem, a

Badinter (1980) trabalha com a ideia de a maternidade não ser um sentimento natural da mulher, e sim sujeito às variações de sentidos conferidos no curso da história. 
saber, da cultura. Para a psicanálise, o processo de subjetivação está sempre inscrito num contexto histórico e social, caracterizado por uma determinada disposição simbólica. "Que não trabalhamos com um sujeito transcendental, mas com os sujeitos encarnados em suas circunstâncias e inseparáveis delas [...] isto já não está pelo menos previsto em Freud e explicitado por Lacan?" (KEHL, 2008, p. 254).

A autora nos lembra das mães da família nuclear burguesa do final do século XIX, que, insatisfeitas com a limitação da vida doméstica e a pobreza da vida sexual, faziam dos filhos o objeto de um pesado investimento libidial. Segundo a psicanalista, o modelo familiar nuclear contribui para as mães fixarem seus filhos no lugar de objetos de amor incestuoso² (KEHL, 2003).

Desse modo, a maternidade aparece não como uma vocação natural ou inata da mulher, tampouco o amor materno é visto como um sentimento inquestionável. Como ser da linguagem, há na mãe uma ignorância estrutural naquilo que concerne a um saber de ordem natural sobre o filho e sobre os objetos que lhe oferece. O objeto materno não é um objeto real ${ }^{3}$; é da ordem de um dom, pertence ao registro do simbólico, à linguagem:

Uma mãe, encarregada por esta sociedade de transmitir este puro real, alicerçada no seu instinto, inevitável e afortunadamente, fracassa. Fracassa porque seu instinto, como para todo o humano, não lhe é suficiente para saber alguma coisa. Esta mãe acerca do seu filho nada sabe e terá que consultar o que na ordem da linguagem se armazena acerca da maternidade e da filiação como saber inconsciente. (JERUSALINSK, 2010, p. 18).

$\mathrm{Na}$ ausência de um dispositivo inato que assegure à mulher um guia sobre o "ser mãe", ela terá que buscar na relação com o grande

A autora "inverte" o complexo de Édipo normal.

A ideia refere-se à impossibilidade de a mãe oferecer ao bebê objetos de satisfação (objeto real) que supram totalmente as necessidades. 
Outro 4 o seu saber inconsciente sobre a maternidade e a filiação. Faz-se necessário "tornar-se" mãe!

\section{A mãe e a função materna}

Coloca-se em evidência o fato de a maternidade estar relacionada ao processo de constituição da mulher como sujeito sexuado ${ }^{5}$. Daí que o lugar da criança no desejo materno está fundamentalmente ligado à sua fantasmática. O modo como se oferecerá e tomará o objeto de seu investimento, o filho, dependerá da sua relação com a falta.

Portanto, o discurso da mãe, o semblante dela, incide na subjetividade da criança. Lacan (2009), no seminário "De um discurso que não fosse semblante", proferido em 1971, refere que todo discurso aparece como semblante, como uma articulação significante: "Um discurso, por natureza, faz semblante [...] é exatamente como objeto daquilo que só se produz no referido discurso que o semblante se coloca." (LACAN, 2009, p. 18). Segundo o psicanalista, um discurso se sustenta a partir da articulação de quatro elementos (agente, o outro, a verdade, o saber), dispostos em lugares e funções distintas. Não é nosso propósito desenvolver tal temática, mas importa dizer que os discursos regem as formas de fazer laço social, e na estrutura de cada discurso, no giro dos elementos, a localização e a função do objeto a indicam diferentes modos de gozar, o "mais-de-gozar"6.

Sabemos da importância dos laços estabelecidos entre a mãe e o bebê, já que deles dependem as condições para o advir do sujeito psíquico. Fleig (2011), ao discutir a complexidade do "tornar-se mãe", ressalta não se tratar meramente de assumir um papel, mas da operação

Lugar da linguagem, do inconsciente, tesouro dos significantes.

Segundo a psicanálise, as concepções de homem e mulher não estão reduzidas ao sexo biológico (características anatômicas e cromossômicas), pois são definidas a partir da sua relação com a linguagem, ou seja, com o campo simbólico. A sexuação é condicionada à travessia do complexo de Édipo, e do seu desfecho depende a identificação do sujeito na posição feminina ou masculina.

6 Lacan busca no conceito de "mais-valia" de Marx (o lucro excedente do capitalista) a ideia do "mais-de-gozar" (gozo suplementar). 
de uma função ${ }^{7}$, ou seja, a função de ser o primeiro outro para o bebê. A mãe ${ }^{8}$ (ou substituto), como Outro primordial, inscreve as necessidades biológicas do filho na linguagem e, por meio do seu olhar, a criança vai construindo uma imagem com a qual estará um dia em condições de se identificar.

Portanto, desde o início, o sujeito recebe sua imagem a partir do campo do outro. O estágio espelho, momento ontológico de constituição do ser, possibilita à criança encontrar no olhar da mãe uma imagem unificada do seu corpo, isto é, as coordenadas para a formação do seu eu.

[...] o estádio do espelho é um drama cujo impulso intenso precipita-se da insuficiência para a antecipação - e que fabrica para o sujeito, apanhado no engodo da identificação espacial, as fantasias que se sucedem desde uma imagem despedaçada do corpo até uma forma de sua totalidade [...] (LACAN, 1998, p. 97).

No entanto, essa imagem não é a imagem real, mas a projeção do desejo materno em relação à criança (CABASSU, 1997). A mãe, na condição de Outro primordial, oferece um lugar ao filho, a partir do qual poderá encontrar significantes que o representem no mundo. Como doadora de significantes, insere o filho numa rede significante intertextual da qual ela mesma faz parte como sujeito desejante.

Por outro lado, se no início é necessária a fusão entre mãe-filho, posteriormente, a entrada de uma presença terceira é fundamental para liberar a criança do aprisionamento ao desejo materno. Ao desejar algo para além do seu bebê e mostrar ser um sujeito faltante, a mãe permite

Segundo Fleig (2011), o termo função é utilizado por Lacan no sentido lógico-matemático, um lugar vazio que somente pode ser operado ao ser preenchido com um valor adequado. Tendo em vista tal ideia, o psicanalista interroga a respeito de qual seria o valor adequado para alguém poder preencher esta função e operá-la para o bebê. Haveria a necessidade de ser um sujeito do sexo feminino?

8 De modo geral, na obra de Lacan, aparece o conceito Desejo de Mãe para designar a função da mãe. Por sua vez, a expressão função materna é mais habitualmente empregada em autores de abordagem lacaniana. 
a entrada do pai na díade, acionando na criança a vivência do complexo de Édipo.

A função paterna é responsável por uma operação fundamental: a castração ${ }^{9}$, que consiste na interdição, e esta introduz uma lei simbólica. Essa lei é responsável pela interdição do incesto e deslocamento da criança da posição de objeto do gozo materno.

Portanto, a função materna implica em cuidados maternos, dupla tradução de linguagem em ação, ação em linguagem e a transmissão da função paterna para o filho (JERUSALINSKY, 1984). Por isso, entendemos não existir função materna sem a presença da função paterna. Uma mãe não pode ser mãe e pai ao mesmo tempo ${ }^{10}$. A operação materna significa a introdução de um terceiro elemento, o significante paterno, que trabalha no sentido de "desviar" o olhar da mãe para além do filho, produzindo aí uma falta. Desse modo, a criança imagina: minha mãe tem outros interesses além de mim. Eu não sou tudo para ela. Essa ruptura, por acionar a falta, tem a propriedade de instaurar as condições para a estruturação de um sujeito desejante. Por isso, ser mãe implica conferir ao filho "um pai simbólico". Por ser simbólico, esse pai não deve ser confundido com o pai de carne e osso, visto que essa função pode ser ocupada pelo pai biológico ou substituto, ou mesmo por outros agentes que representem a lei, como um tio, um(a) avô(ó) ou um padrinho.

Lacan (1999) frisou a importância de considerar as questões relativas à carência paterna mais em termos de sua operatividade no

9 Na teoria psicanalítica, o termo castração não corresponde à mutilação dos órgãos sexuais masculinos, mas indica uma experiência inconsciente vivenciada pela criança, pela primeira vez, quando reconhece (angustia de castração) a diferença anatômica dos sexos. Ao longo da vida, o sujeito revive constantemente a experiência da castração. Em Lacan, esse termo é utilizado para designar um corte no vínculo mãe-filho (NASIO, 1997).

10 No cenário atual, as famílias organizadas em torno da mulher é uma realidade cada vez mais comum. Nesses grupos familiares, muitas mães aparecem como sendo a pessoa responsável pelos cuidados, educação e provimento dos filhos. Nesse sentido, podemos dizer que essas mães desempenham o papel de cuidarem sozinhas dos filhos, porém, isso não é o mesmo que desempenhar a função. A presença ou ausência de um terceiro simbólico (função paterna) na relação da mãe com os filhos independe da configuração familiar. Salientamos ser o significante paterno introduzido através do discurso materno. 
complexo de Édipo do que da sua presença ou ausência no ambiente. A entrada de um terceiro na relação mãe-filho é fundamental no advir psíquico do sujeito-filho, pois a sua ausência ou insuficiência pode acarretar vários prejuízos para o desenvolvimento da criança: "Existe um problema, na medida em que a posição do pai é posta em dúvida pelo fato de não ser sua palavra que serve de lei para a mãe" (LACAN, 1999, p. 199).

Assim, evidenciamos a importância da posição subjetiva da mãe em relação ao filho, pois, no início, a criança está para a mãe na condição de objeto, de falo. Por sua insuficiência, no começo da vida, o pequeno fica completamente assujeitado aos caprichos maternos.

A lei da mãe, é claro, é o fato de que a mãe é um ser falante, e isso basta para legitimar que eu diga a lei da mãe. Não obstante, essa lei é, por assim dizer, uma lei não controlada. Reside simplesmente, ao menos para o sujeito, no fato de que alguma coisa em seu desejo é completamente dependente de alguma outra coisa, que sem dúvida já se articula como tal, e que é realmente da ordem da lei, só que essa lei está, toda ela, no sujeito que a sustenta, isto é, no bem-querer ou malquerer da mãe, na mãe boa ou má. (LACAN, 1999, p. 195).

Freud e Lacan enfatizaram o valor fálico do filho na relação com a mãe, assim como a importância da castração como um ato de corte sobre o desejo materno para limitar o gozo. Importante salientar que a castração incide não apenas na criança, mas também na mãe. Em outros termos, a castração ocorre sobre o vínculo mãe-filho, colocando um fim na crença da mãe de ter o falo e na do filho que acredita sê-lo (NASIO, 1997).

A função paterna é a responsável pelo descolamento da criança da posição de objeto de gozo materno para a de sujeito do desejo. A sua importância reside em introduzir na criança uma estrutura que ordena o seu desejo em relação à linguagem. Dito de outro modo, o Desejo de Mãe (DM) deve ceder lugar ao Nome do Pai (NP) e à instalação da metáfora paterna para ocorrer uma limitação no desejo de fazer Um entre 
mãe-criança. Todavia, essa operação somente ocorrerá se houver a inscrição da função paterna e do Nome do Pai na mulher-mãe. Portanto, o destino da criança, como sujeito ou objeto, dependerá do lugar que o inconsciente materno Ihe reserva (SOLER, 2005). Lembramos que o pai tem entrada na vida subjetiva da criança através da palavra da mãe, e somente se esta desejar.

Assim, Lacan fala da importância capital da mãe e do seu desejo. Compara-o a um grande crocodilo, em cuja boca a criança fica ameaçada de ser engolida. Contudo, há na boca do crocodilo, na boca da mãe, algo que pode emperrar e salvar a criança: o desejo da mãe pelo pai, por um nome, para além do filho (LACAN, 1999). O desejo materno tem a propriedade de lançar o sujeito para a vida ou condená-lo a ser um "filho rolha" que tampona a falta mãe (LACAN, 1981). De certo modo, a maternidade, tomada na cultura como sendo o "paraíso", reflete o gozo presente na relação mãe-filho. Diz Jerusalinsky (2010, p. 19): "[...] a mãe desejaria ser tudo para seu filho, tanto quanto ela desejaria que seu filho fosse tudo para ela". Por isso o semblante da mãe feliz: a "mãe é toda".

Todavia, sabe-se que essa plenitude tem o preço de endereçar ao filho um voto de morte. A inscrição da falta promove a vida por acionar o desejo: "Que ela não seja tudo, e que o filho também não o seja, os leva a precisar de outra coisa. Ou seja, os leva, paradoxalmente, a desejar" (JERUSALINSKY, 2010, p. 19). Por isso, padece: precisa liberar o filho para o mundo, conceder um passaporte para que possa ser um sujeito do mundo.

O semblante da mãe feliz, por vezes melancólico, encontrado nas representações da cultura mostra ter certa relação com a verdade ${ }^{11}$ : "A verdade não é o contrário do semblante". (LACAN, 2009, p. 26-27). Podemos dizer que a verdade sustenta o semblante.

11 Verdade do desejo inconsciente. 


\section{Da mãe-toda à alienação parental}

A contemporaneidade trouxe consigo profundas transformações em todos os campos da existência humana. As mudanças nos discursos e nos laços sociais, decorrentes do curso da história, têm produzido novos sentidos e novos semblantes. Percebemos, por exemplo, as mudanças relacionadas aos sentidos da masculinidade e da paternidade, pois ser homem e pai na atualidade não implica ter que ser "macho", "autoritário", tampouco ter "distância afetiva" dos filhos, tal como ocorria há poucas décadas.

Assim como os homens, as mulheres da contemporaneidade vivem novas realidades relacionadas ao seu papel na sociedade. Há menos de um século, o lugar social da mulher era a família e o espaço doméstico, sendo a maternidade o seu único destino. Na ordem familiar burguesa do século XIX, a feminilidade e a maternidade eram consideradas indissociáveis, sendo os filhos o valor narcísico maior da mulher, principalmente quando estes eram homens.

Hoje, encontramos um novo cenário social, no qual as mulheres têm a possibilidade de uma vida profissional e financeira, com outros destinos além de tornar-se mãe. Além disso, há na contemporaneidade novas e múltiplas configurações da família, dentre as quais aparecem as "famílias recompostas", "multiparentais" e "monoparentais". Roudinesco (2003), ao discutir as mudanças nos arranjos familiares, assim como os avanços da ciência relativos às técnicas de contracepção e procriação, aponta os efeitos nas relações familiares, salientando o poder crescente assumido pela mulher na constelação familiar.

Na modernidade, primeiro surgiu a família "tradicional", cuja missão era a transmissão do patrimônio. Comandada pela autoridade patriarcal, o pai encarnava a figura do suserano e da divindade. Em seguida, a família "moderna", fundada no amor romântico, sacralizado através do casamento, valorizando a divisão de trabalho entre marido e mulher e depositando no Estado a responsabilidade pela educação do filho. Por fim, desde 1960, emerge a família "contemporânea", ou "pós-moderna", 
na qual há uma união de duração relativa entre indivíduos que buscam relações íntimas ou realização sexual. Sujeita aos divórcios, separações e recomposições, na família atual, a transmissão da autoridade é uma questão problemática (ROUDINESCO, 2003).

No tecido social contemporâneo, a emergência do feminino e do poder da mãe nas novas configurações familiares é algo a ser observado. Atualmente, há um número ${ }^{12}$ significativo de mulheres, por diversos motivos, vivendo sem cônjuge e com os filhos - situação em que "chefiam" a casa e cuidam dos filhos. Em referência a esse contexto, Roudinesco (2003) lança uma interessante questão sobre o possível nascimento de uma onipotência do "materno" no lugar do antigo poder do masculino e do "paterno".

Como vimos, as família da atualidade têm sido compostas por diversos arranjos e, muitas vezes, a figura do pai concreto está ausente. Neste momento, entendemos ser fundamental indicar a diferença entre o pai como imago e a função paterna. A imago encontra-se relacionada à imagem internalizada da figura paterna, ao passo que a função diz respeito à ordem simbólica e independe da presença ou ausência do pai. Por função, compreende-se o exercício de uma nomeação que permite à criança ter acesso a uma identidade (ROUDINESCO, 1998).

Fleig (2008) aponta as relações entre as formas de neuroses dominantes numa época e as mudanças nas condições da família, tal como ocorreu na modernidade, quando houve a dilapidação do pai como efeito do declínio paterno. Apesar do enfraquecimento do pai moderno, o declínio da imago paterna deflagrada pelo processo histórico não coincide com a função paterna ${ }^{13}$. O pai enquanto função continua a

12 A mulher sem cônjuge e com filho aparece nas estatísticas compondo $17,4 \%$ da população brasileira no ano de 2009, sendo esse número basicamente equivalente ao do casal sem filho (17,15\%). Segundo o IBGE (2010), houve nos últimos anos um aumento em relação a esse novo padrão de família, a mulher sem cônjuge com filho. Além disso, desde a década de 1980, vem crescendo continuadamente o número de mulheres como sendo a pessoa de "referência da família" (IBGE, 2010) ou "chefes" da família. Tal informação significa que 22 milhões de mulheres brasileiras estão à frente de seus lares (BERTELLI, online, 2009)

13 A função paterna é a operação de instalação do significante "Nome do Pai" (NP) no lugar do "Desejo da Mãe" (DM), que produz um corte na relação da mãe-filho (LACAN, 1999). 
ser o organizador fundamental da subjetividade e da cultura. A função paterna é uma operação estrutural tanto para o sujeito como para o social, podendo ser encarnada por vários agentes.

Lacan, nos "Complexos familiares", publicado em 1938, já antecipava o debate relativo ao declínio da figura do pai na família nuclear burguesa, mostrando existir uma relação entre a carência do pai e a produção das neuroses contemporâneas.

Quanto à família tradicional, fundada no sistema patriarcal e nas relações de parentesco, Fleig (2011) entende ser o desaparecimento o seu destino. Tendo em vista esse cenário, propõe uma reflexão acerca dos efeitos subjetivos relacionados às mudanças no âmbito da família contemporânea, especialmente naquilo que concerne ao desfalcamento do pai nos grupos familiares. Nesse sentido, interroga o possível surgimento de um matriarcado no lugar do antigo patriarcado. Qual seria o lugar conferido ao pai como função na família da atualidade? Conforme o psicanalista, a chave da leitura freudiana está na relação com o pai, pois ele representa a civilização. Por conseguinte, o pai aparece como a fonte do mal-estar do homem na cultura moderna. Seguindo essa abordagem, Lacan trabalha as consequências da dilapidação do pai e da sua consistência, expressa na figura do pai humilhado.

A formação de catástrofes estruturais no processo de constituição do sujeito seria determinada pelo tipo de grupo familiar, sua composição, sua inserção social e o valor que aí tem seu chefe, o pai. Ora, a família moderna, desfalcada do pai, propicia as condições favoráveis para a estagnação da maturação subjetiva e para eclosão da psicose. (FLEIG, 2011, p. 5).

Freud mostrou ser a família um lugar fecundo de produção de subjetividades e patologias. Os pais ou os substitutos, no exercício das funções parentais, operam um golpe de força na estruturação psíquica dos sujeitos. "Golpe de força" é uma expressão utilizada por Bergès e Balbo (2010) para designar a força pujante da mãe, como Outro primordial, na constituição subjetiva da criança. No transitivismo 
(relação especular), a mãe tem a força de fazer hipóteses, de antecipar as potencialidades do filho e instalar o significante daquilo que falta no Outro, a saber, o simbólico. A competência da mãe para exercer um golpe de força ocorre à medida que a criança está dissociada do corpo materno, e tal separação se dá em decorrência da presença do discurso do pai no discurso da mãe. Dizem Bergès e Balbo (2010):

Para que a mãe permita à sua criança ter acesso a Verneinung, ainda é preciso que seu próprio discurso seja marcado pela função paterna, aquela que nós sustentamos justamente que é significante da falta no Outro. Aqui, o Outro articulará e suporá na sua criança seu golpe de força ${ }^{14}$. Assim, o próprio Outro da criança poderá se dividir do de sua mãe, senão a criança seria apenas a réplica em espelho. (BERGĖS; BALBO, 2010, p. 66).

A nosso ver, o pai (um terceiro) incide como golpe de força à medida que sua presença produz efeitos sobre a mãe, colocando fim na crença materna de fazer Um com o filho.

Lacan (2008), despojado de pretensões educativas ou moralistas relativas ao "afrouxamento do liame familiar" (p. 59), frisa ser o destino psicológico da criança intimamente relacionado às imagos parentais, acentuando o caráter problemático dos conflitos do casal nos filhos:

É por aí que o desentendimento dos pais é sempre prejudicial à criança, e que, se nenhuma lembrança permanece mais sensível em sua memória que a confissão formulada do caráter desarmonioso de sua união, as formas mais secretas do desentendimento não são menos perniciosas. Nenhuma conjuntura é, com efeito, mais favorável à identificação acima invocada como neurotizante do que a percepção, muito certa na criança, nas relações dos pais, do sentido neurótico das barreiras que os separam, e muito especialmente no pai, em virtude da função reveladora de sua imagem no processo de sublimação sexual. (LACAN, 2008, p. 90).

14 Grifo da autora do artigo. 
Como consequência da inoperância do pai, o filho é condenado a buscar indefinidamente o desligamento da "mãe-toda"15, e daí pode surgir uma série de condutas e/ou patologias, salienta o psicanalista. Dentre estas, as fugas na infância, os rompimentos conturbados na idade adulta, a presença de um narcisismo exacerbado na base de certas formas de suicídio não violento, tal como nas neuroses orais, digestivas, na hipocondria e nas preocupações relacionadas à ingestão e excreção alimentar, assim como em comportamentos de isolamento social.

Ao buscar responder às demandas do campo do Outro e obturar a falta materna, o filho sacrifica sua existência como sujeito desejante e aceita permanecer na condição de falo da mãe. Nessa posição, poderá ficar prensado na boca do jacaré e ser por ele engolfado.

Por outro lado, o desejo de uma mulher por um homem implica existir nela uma falta, e dele deseja receber o que não tem: o falo. Diz Lacan (2009, p. 65): "Daí resulta que uma mulher só tem um testemunho de sua inserção na lei, daquilo que supre a relação, através do desejo de um homem". Ao endereçar um clamor de completude apenas ao filho e a mais ninguém, a mulher-mãe convoca a criança a ocupar o lugar de falo, de objeto de gozo. A mãe em excesso, ou a mãe-toda, representa nada mais do que a inoperância da função materna. Por isso, entendemos ser a maternidade uma operação marcada pela Lei.

Bernardino (2010) mostra a Lei como um ponto de confluência entre a psicanálise e o direito, a saber, a Lei simbólica e a Lei judiciária. No âmbito Judiciário, a lei do divórcio direto no Brasil, promulgada pelo Congresso Nacional desde 2010, tem permitido a dissolução imediata do casamento. Dada a fragilidade dos laços conjugais na atualidade, muitos casais têm optado pela separação como a solução para os conflitos. Todavia, nem sempre o processo de separação ocorre de forma pacífica, e pode ser ainda mais complicado quando os cônjuges

15 A mãe como potência; não-castrada. 
envolvem os filhos nas desavenças matrimoniais. Por vezes, a regulação da guarda ou visitação dos filhos encontra na Justiça uma resolução eficaz. Todavia, há vários casos em que as crianças são colocadas no centro dos embates travados pelos pais nas varas de família.

Dadas as mudanças nos papéis sociais do homem e da mulher e na horizontalidade das relações no grupo familiar, hoje, não é incomum o homem reivindicar a guarda ou a guarda compartilhada dos filhos e solicitar flexibilidade nos direitos de convivência com eles. Entendemos existir nesse movimento dos homens-pais uma posição discursiva distinta daquela assumida há poucos anos, quando a guarda da mãe era praticamente inquestionável.

Com as mudanças nos discursos e nos modos de os sujeitos se relacionarem, surgiram novas formas de distribuição do gozo, a partir dos semblantes da cultura atual. No caso da alienação parental ${ }^{16}$, apareceram personagens como mães vitimadas pela ruptura da união conjugal e pais desqualificados pela acusação de abandono, ambos em disputa pelos filhos. Essa realidade tem produzido sérios impasses e desacordos entre os cônjuges, afetando profundamente os filhos, tal como atestam profissionais do campo da saúde, do direito e da Justiça.

Segundo Dias (2009), ex-desembargadora do Tribunal de Justiça do Rio Grande do Sul, esse fenômeno não é novo, mas tem sido recorrente nas práticas dos profissionais ligados ao direito de família. A síndrome de alienação parental, ou implantação de falsas memórias, caracterizase como um quadro em que um genitor ressentido e desejoso de vingarse do outro afasta o filho, criando uma série de situações para dificultar ao máximo ou impedir os contatos. Como resultado desse processo, o filho acaba por odiar o pai.

16 Tratamos, neste artigo, da mãe como sendo a progenitora alienadora e o pai como o progenitor alienado. Apesar de a mulher aparecer mais comumente como agente causa da alienação parental, há homens que geram tal situação. Além disso, o quadro de alienação parental também ocorre em filhos de casais que vivem juntos, ou seja, não estão divorciados. 
A designação síndrome da alienação parental foi proposta pelo psiquiatra americano Richard Gardner, em 1985, para indicar a situação em que a mãe ou o pai de uma criança a treina para romper os laços afetivos com o outro genitor, produzindo intensos sentimentos de ansiedade e medo (SAP, online, 2011). Mesmo sendo frequentemente utilizado pelos profissionais da saúde e dos direitos da família, o termo síndrome da alienação parental não aparece como um quadro psiquiátrico reconhecido nas classificações de diagnósticos de saúde mental, como o DSM-IV.

De toda forma, dada a recorrência do fenômeno, medidas legais foram adotadas contra a alienação parental. No Brasil, desde agosto de 2010, vigora a Lei da Alienação Parental, que prevê medidas como: acompanhamento psicológico, multa, ou mesmo a perda da guarda da criança a pais que estiverem alienando os filhos (SAP, online, 2011).

Dias (2009) refere existir na alienação uma verdadeira campanha para desmoralizar o genitor, sendo o filho utilizado como instrumento da agressividade direcionada ao cônjuge. A mãe monitora o tempo do filho com o pai e os seus sentimentos. O afastamento destrói o vínculo entre pai e filho, levando a criança a ser órfã do genitor alienado e a identificarse com o genitor patológico, passando a aceitar como verdadeiro tudo que lhe é informado: "O detentor da guarda, ao destruir a relação do filho com o outro, assume o controle total. Tornam-se unos, inseparáveis. 0 pai passa a ser considerado um invasor, um intruso a ser afastado a qualquer preço" (DIAS, 2009, p. 46).

De acordo com a autora, o alienador encontra prazer nas manobras utilizadas para aniquilar o outro genitor, valendo-se das mais diversas manipulações, inclusive produzindo acusações de abuso sexual e implantando na criança uma versão distorcida dos fatos. "Com o tempo, nem a mãe consegue distinguir a diferença entre verdade e mentira. A sua verdade passa a ser verdade para o filho, que vive com falsas personagens de uma falsa existência, implantando-se, assim, falsas memórias." (DIAS, 2009, p. 46-47). 
Visto a gravidade da denúncia da mãe, em geral, o Poder Judiciário impõe rapidamente o afastamento do filho do convívio paterno, produzindo-se uma ruptura no vínculo parental.

Antes, referimos que o discurso se mostra como semblante, e nessa aparência do ser a dimensão da verdade ${ }^{17}$ se revela. Segundo Lacan (2009), existe uma conjunção entre o ser e o parecer, pois os semblantes não são formações enganosas ou simulacros. O semblante é mais do que fazer-se de... ou querer se passar por, pois mesmo na construção de uma mentira ou de uma ficção o sujeito comunica algo da verdade do seu desejo. A verdade, definida pela relação dos fatos, se mostra mesmo quando o sujeito nada quer saber dela. O semblante vitimado ou triunfante da mãe alienadora mostra uma parcela da sua verdade $^{18}$ : o desejo da posse exclusiva do filho. A criança tomada pelo discurso materno vê-se à mercê da demanda onipotente e absoluta da mãe de ser a única pessoa importante na sua vida. Como um oráculo, coloca-se no lugar da verdade e obstaculiza o caminho do filho de tornarse um sujeito do desejo.

A crença da mulher de não precisar de um pai para o filho mostra a fantasia de querer ser uma potência fálica. "Assim, muito além da castração, ela poderia ser mulher - toda. [...] para que a mulher exista ${ }^{19}$ é preciso inventar uma filiação que exclua o homem, ou seja, a mulher se transforma em Mãe uma vez que é ela quem pode filiar sozinha." (TAVARES, 2010, p. 71).

A fim de concluir, trazemos um pequeno recorte do filme $A$ morte inventada (2009), do diretor Alan Minas, no qual podemos vislumbrar as consequências do golpe de força da mãe. De modo poético e sensível, a trama mostra a difícil experiência de pais e filhos que viveram a alienação parental. Ao longo da narrativa, descortinam-se as histórias

Verdade do inconsciente.

A verdade não é toda.

Lacan diz não existir um universal que defina a mulher, por isso utiliza o aforismo "a mulher não existe". 
e os sofrimentos, bem como a ambivalência dos filhos, o amor e o ódio endereçados à mãe-toda. Diz o relato de uma das jovens: "A minha mãe era tudo para mim, mas essa mãe maravilhosa falava muito mal do meu pai, então eu cresci com esse ódio do meu pai". Embora submetida ao desejo da mãe, a órfão de pai vivo recebe a verdade que oculta e sustenta o semblante materno:

Então num certo momento comecei a fazer uma busca pela verdade, foi quando eu fui atrás de saber o que tinha acontecido mesmo, aquelas histórias todas que ela me contava, o quê que tinha de verdade naquilo? Aí eu descobri que não tinha nada, que era tudo mentira mesmo. Que tudo que tinha vivido na infância e na adolescência tinha sido uma mentira contada pela minha mãe. (A MORTE..., 2011).

\section{Considerações finais}

Vimos nesse percorrido que a alienação parental decorre da posição subjetiva assumida pela mãe em relação ao filho. A mãe fálica toma a criança como objeto do seu gozo mortífero. Por ser uma mãe narcisista, não deseja dividir o filho com mais ninguém. Daí, o seu golpe de força desafia a consistência do golpe de força do pai. Nas falas dos jovens do filme, de um lado surge a profunda mágoa dirigida à mãe alienadora, e do outro emerge o ressentimento em relação ao pai alienado por não ter sido suficientemente capaz de enfrentar a pujança da mulher.

A função materna, além dos cuidados maternos, significa transmitir ao filho a Lei do pai. Podemos pensar na hipótese de algumas famílias buscarem instaurar a Lei simbólica, organizadora dos laços amorosos e sociais, através da Lei do Judiciário. Em casos nos quais há comprovação de uma falsa denuncia de abuso sexual do pai em relação ao(à) filho(a), a mãe perde a guarda da criança. A Lei promulgada por uma autoridade legal, além de produzir um corte na convivência parental, pode incidir como um corte simbólico na relação da mãe-filho. 
Tendo em vista a complexidade do trabalho materno, a mãe precisa encontrar um equilíbrio naquilo que concerne à sua presença e à sua ausência com a criança. Em outras palavras, precisa estar presente, sem devastar. Precisa estar ausente, sem faltar em excesso.

Apesar de a mãe ser representada na cultura como o bem supremo e a encarnação da benevolência, ela também surge nas fábulas infantis e nas obras clássicas da literatura em personagens como as madrastas e as bruxas sinistras, que mostram um lado mais sombrio da imago materna. A mãe é uma só, mas os semblantes de mães são muitos.

\section{Referências}

A MORTE inventada. Disponível em: <http://antropologiasocial.com.br/ wp-content/uploads/2011/01/a-morte-inventada.pdf>. Acesso em: 08 jul. 2011.

BADINTER, E. Um amor conquistado: o mito do amor materno. São Paulo: Círculo do Livro, 1980.

BERNARDINO, L. M. F. Mãe é uma só? In: CALLIGARIS, Contardo (Org.). Educa-se uma criança? Porto Alegre: Artes e Ofícios, 2010. p. 75-84.

CABASSU, G. Palavras em torno do berço. In: WANDERLEY, D. (Org.). Palavras em torno do berço. Salvador: Ágalma, 1997. p. 21-35.

DIAS, M. B. Síndrome de alienação parental, o que é isso? Revista do çao civil, Belém, ano 11, n. 15, jan.-dez. 2009. Disponível em: <http:// pt.scribd.com/doc/49814270/REVISTA-DO-CAO-CIVEL-15-3>. Acesso em 10 jun. 2011.

FLEIG, M. O pai moderno dilapidado: efeito do declínio patriarcal, 2008. Revista do Instituto Humanitas Unisinos, Rio Grande do Sul. Disponível em:

<http://www.ihuonline.unisinos.br/index.php?option=com_tema_capa\&l temid=23\&task=detalhe\&id=1201>. Acesso em: 25 jun. 2010. 
FLEIG, M. O desaparecimento da família tradicional, 2011. Revista do Instituto Humanitas Unisinos, Rio Grande do Sul. Disponível em: <http://www.ihuonline.unisinos.br/index.php?option=com_content\&view =article\&id=3801\&secao=359>. Acesso em: 28 jun. 2011.

KEHL, M. R. Em defesa da família tentacular. Artigos e ensaios. 2003. Disponível em: <http://www.mariaritakehl.psc.br/PDF/ emdefesadafamiliatentacular.pdf>. Acesso em: 29 set. 2010.

. Deslocamento do feminino. Rio de Janeiro: Imago, 2008.

INSTITUTO BRASILEIRO DE GEOGRAFIA E ESTATÍSTICA (IBGE). Síntese de indicadores sociais: uma análise das condições de vida da população brasileira. Disponível em: <http://www.ibge.gov. br/home/estatistica/populacao/condicaodevida/indicadoresminimos/ sinteseindicsociais2010/SIS_2010.pdf>. Acesso em: 01 out. 2010.

JERUSALINSKY, A. Psicanálise do autismo. Porto Alegre: Artes Médicas, 1984.

. Psicanálise e desenvolvimento infantil. Porto Alegre: Artes e Ofícios, 2007.

- Apesar de você, amanhã há de ser outro dia. In: CALLIGARIS, ContaRdo (ORG.). Educa-se uma criança? Porto Alegre: Artes e Ofícios, 2010. p. 13-23.

LACAN, J. O estádio do espelho como formador da função do eu. (1949) In: LACAN, J. Escritos. Rio de Janeiro: Zahar, 1998. p. 77-86.

- O Seminário, Livro 5. As formações do inconsciente. Rio de Janeiro: Zahar, 1999.

Zahar, 1992.

Seminário, Livro 17. O avesso da psicanálise. Rio de Janeiro:

. O Seminário, Livro 18. E um discurso que não fosse semblante. Rio de Janeiro: Zahar, 2009. 1981.

. O Seminário, Livro 20. Mais, ainda. Rio de Janeiro: Zahar, 
. Os complexos familiares. Rio de Janeiro: Zahar, 2008.

ROFULFO, R. O brincar e o significante: um estudo psicanalítico sobre a constituição precoce. Porto Alegre: Artes Médicas, 1990.

ROUDINESCO, E.; PLON, M. Dicionário de psicanálise. Rio de Janeiro: Zahar, 1998.

ROUDINESCO, E. A família em desordem. Rio de Janeiro: Zahar, 2003.

SARAMAGO, J. Filhos são do mundo. Disponível em: <http://www. umdoistres.com.br/artigos/outubro2010/filhos.htm>. Acesso em 08 jul. 2011.

SOLER, C. O que Lacan dizia das mulheres. Rio de Janeiro: Zahar, 2005.

TAVARES, E. A mãe de proveta. In: CALLIGARIS, Contardo (Org.). Educa-se uma criança? Porto Alegre: Artes e Ofícios, 2010. p. 63-74.

BERTELLI, Chris. PNAD: número de mulheres chefes de família cresce em 19 Estados. Último Segundo, São Paulo, 08 set. 2010. Disponível em: <http://ultimosegundo.ig.com.br/brasil/pnad+numero+de+mulheres +chefes+de+familia+cresce+em+19+estados/n1237771177940.html>. Acesso em: 07 out. 2010.

SAP: Síndrome de alienação parental. Disponível em: <http://www. alienacaoparental.com.br/o-que-e >. Acesso em: 07 jul. 2011.

Recebido em: 15/09/2014

Aprovado em: 01/07/2015 